\title{
Treatment and Recycling of the Process Water in Iron Ore Flotation of Yuanjiacun Iron Mine
}

\author{
Wen-li Jiang ${ }^{1}$ and Hai-feng $\mathrm{Xu}^{2}$ \\ ${ }^{1}$ School of Resources and Environmental Engineering, Wuhan University of Technology, Wuhan 430070, China \\ ${ }^{2}$ Changsha Research Institute of Ming and Metallurgy Co., Ltd., Changsha 410012, China \\ Correspondence should be addressed to Hai-feng Xu; xuhaifeng0425@126.com
}

Received 23 May 2017; Accepted 4 July 2017; Published 8 August 2017

Academic Editor: Wenshan Guo

Copyright (c) 2017 Wen-li Jiang and Hai-feng Xu. This is an open access article distributed under the Creative Commons Attribution License, which permits unrestricted use, distribution, and reproduction in any medium, provided the original work is properly cited.

\begin{abstract}
Coagulating sedimentation and oxidation treatment of process water in iron ore flotation of Yuanjiacun iron mine had been studied. The process water of this mine carried residual polyacrylamide (PAM), poly(diallyldimethylammonium chloride) (PDADMAC), and $\mathrm{Ca}^{2+}$ from the flotation and caused decrease of the iron flotation recovery or grade of the concentrate. The studies on highintensity magnetic separation (HIMS) tailings for coagulating sedimentation showed that the settling performance of coagulant (named CYH) was better than that of PDADMAC. The analyses of FTIR spectra and zeta potential demonstrated that CYH is adsorbed mainly through electrostatic attraction onto HIMS tailings. Sodium hypochlorite was adopted to oxidize the residual organics in tailings wastewater. When sodium hypochlorite is at the dosage of $1.0 \mathrm{~g} / \mathrm{L}$, reaction temperature is of $20^{\circ} \mathrm{C}$, and reaction time is of 30 minutes, the removal rates of PAM, COD, and $\mathrm{Ca}^{2+}$ were $90.48 \%, 83.97 \%$, and $85.00 \%$, respectively. Bench-scale flotation studies on the treated tailings wastewater indicated that the iron recovery and grade of concentrate were close to those of freshwater.
\end{abstract}

\section{Introduction}

Iron ore resources are extremely rich in China, but most of them belong to complex ultrafine iron ore with high content of impurities [1]. Reverse flotation has been proved to be an efficient process for economic reasons [2-6]. In order to ensure iron concentrate grade and iron recovery, a large number of processing reagents are selected and applied in the iron ore beneficiation. The process water carried plenty of residual processing reagents, and such wastewater with color depth and strong smell could seriously affect the environment and the local people. Prevailing campaign for a cleaner and safer environment with clean surface water and ground water has led to increased recycling of process water within the production cycle of mineral flotation [7]. Since the chemistry property of process water is entirely different from fresh water, there is a concern about the possible effects of the contained components on the efficiency of the flotation process [8]. In iron ore flotation process, a large amount of $\mathrm{NaOH}$ is taken to adjust the $\mathrm{pH}$. The wastewater $\mathrm{pH}$ of iron ore is more than 9 , so physicochemical treatment of iron wastewater from a certain degree is rather difficult [9]. At present, the common methods of treatment of wastewater from flotation are acid-alkali neutralization $[10,11]$, precipitation, coagulation, and sedimentation [12-15], chemical oxidation degradation [16], constructed wetland [17-19], ion exchange method [20], adsorption method [21, $22]$, and biological method [23, 24]. However, the single method above cannot completely clear wastewater pollution with harsh operating conditions. In addition, they may also produce secondary pollution.

Yuanjiacun iron mine of Shanxi province in China is the largest iron mine of micrograined hematite combined with magnetite in Asia. The annual processing capacity of iron ore reaches 22 million tons, and the wastewater from mineral processing is about 400 thousand $\mathrm{m}^{3}$ every day. If the dressing wastewater is directly discharged into the nature, it will not only pollute the surrounding environment but also has a great potential safety risk. Recycling of process water is a good way to solve the problem. In this study, the influence of tailings wastewater components were investigated on flotation of hematite in order to assess the practicability of 
TABLE 1: Wastewater quality monitoring data.

\begin{tabular}{lccccccc}
\hline Wastewater index & $\mathrm{pH}$ & $\mathrm{SS} /\left(\mathrm{mg} \cdot \mathrm{L}^{-1}\right)$ & $\mathrm{Ca}^{2+} /\left(\mathrm{mg} \cdot \mathrm{L}^{-1}\right)$ & $\mathrm{Cl}^{-} /\left(\mathrm{mg} \cdot \mathrm{L}^{-1}\right)$ & $\mathrm{TFe} /\left(\mathrm{mg} \cdot \mathrm{L}^{-1}\right)$ & $\mathrm{PAM} /\left(\mathrm{mg} \cdot \mathrm{L}^{-1}\right)$ & $\mathrm{COD} /\left(\mathrm{mg} \cdot \mathrm{L}^{-1}\right)$ \\
\hline Content & 9.12 & 178 & 240 & 210 & 4.97 & 3.15 & 131 \\
\hline
\end{tabular}

TABle 2: Particle size distribution of samples.

\begin{tabular}{lcccccccc}
\hline \multicolumn{2}{l}{ Size fraction/mm } & +0.075 & $\begin{array}{c}-0.075 \\
+0.045\end{array}$ & $\begin{array}{c}-0.045 \\
+0.038\end{array}$ & $\begin{array}{c}-0.038 \\
+0.030\end{array}$ & $\begin{array}{r}-0.030 \\
+0.015\end{array}$ & $\begin{array}{c}-0.015 \\
+0.010\end{array}$ & -0.010 \\
\hline \multirow{2}{*}{ Yield/\% } & Individual & 3.14 & 5.37 & 2.50 & 5.42 & 10.57 & 42.35 & 30.65 \\
& Aggregate & 3.14 & 8.51 & 11.01 & 16.43 & 27.00 & 69.35 & 100 \\
\hline
\end{tabular}

recycling process water in flotation practice first. A novel coagulant $\mathrm{CYH}$ was introduced to coagulate HIMS tailings, and the coagulating sedimentation mechanism of CYH was investigated by FTIR spectra and zeta potential. Moreover, sodium hypochlorite was adopted to oxidize the organic pharmaceutical residues in wastewater. Besides, the effect of wastewater treatment was evaluated by recycling of tailings wastewater.

\section{Experiment}

2.1. Materials and Reagents. All test samples including tailings wastewater, high-intensity magnetic separation (HIMS) tailings, and flotation samples were procured from the Yuanjiacun iron mine concentrator of Shanxi province in China. The tailings wastewater was collected from flotation tailings water combined with magnetic separation tailings water, stirred evenly, and stored in plastic bottle. The wastewater quality was shown in Table 1 . Test results showed that the tailings wastewater presented yellowish brown, suspended solids (SS) content and the concentration of $\mathrm{Ca}^{2+}, \mathrm{Cl}^{-}$, and COD exceeded the standard.

The concentration of the HIMS tailings pulp was $11.93 \%$ by weight, and the main minerals were quartz $(62.54 \%)$, amphibole $(17.44 \%)$, chlorite $(4.16 \%)$, hematite (4.75\%), montmorillonite (3.82\%), calcite $(2.93 \%)$, and feldspar (4.36\%). The XRD analysis of the sample was shown as Figure 1. The sample was classified into different size fractions as shown in Table 2. As shown in Table 2, most particle size of the sample was fine and more, even if the sample was on quiescent standing in a month, it also would not naturally subside.

The samples for flotation were taken from on-site samples of flotation, which were ground to $95 \%$ passing $0.045 \mathrm{~mm}$, and contained $34.90 \%$ specularite and hematite, $8.70 \%$ magnetite, $0.20 \%$ limonite, $39.40 \%$ quartz, $11.40 \%$ chlorite and hornblende, and $4.90 \%$ calcite and dolomite.

Coagulant $(\mathrm{CYH})$ of the molecular weight of 80 thousands was synthesized in our lab and it was of technical grade. Amphoteric polyacrylamide (PAM) of the molecular weight of 12 million was of technical grade. Collector (named RA715) and coagulant poly(diallyldimethylammonium chloride) (PDADMAC) were from the Yuanjiacun iron mine concentrator of Shanxi province in China and they were of all technical grade. $\mathrm{CaCl}_{2}$ and $\mathrm{NaCl}$ acted as sources of $\mathrm{Ca}^{2+}$ and $\mathrm{Cl}^{-}$ions, respectively. Other chemical materials were

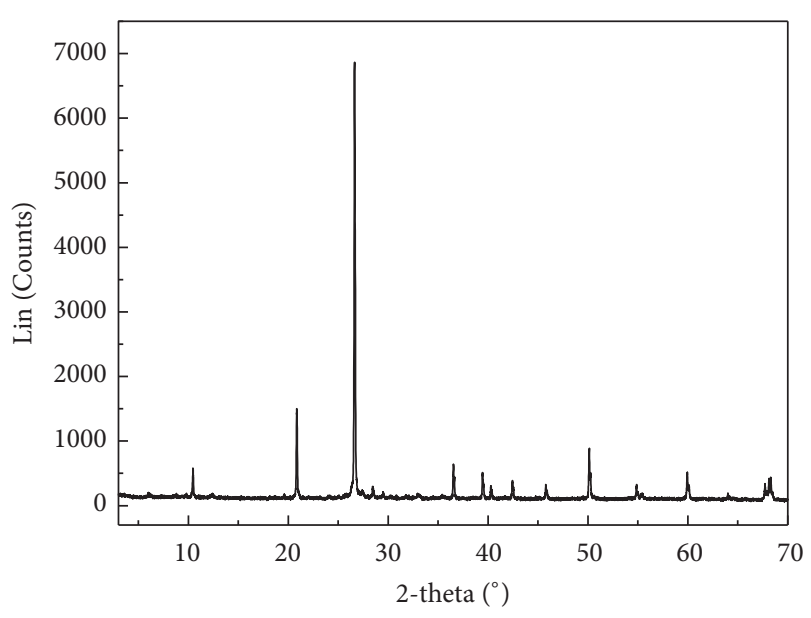

FIGURE 1: XRD analysis of the HIMS tailings sample.

bought from commercial companies and their purity was above chemical purity grade.

2.2. Coagulating Sedimentation Experiments. Use $300 \mathrm{~mL}$ HIMS tailings pulp mentioned above at every turn to conduct coagulation contrast test. First, add the required amount of CYH into the testing pulp, and mix them up evenly; then add PAM into the testing pulp, and after a period of stirring, leave the samples standing and record the height of supernatant as a function of standing time.

2.3. Oxidation-Sedimentation Experiments. Use $1.0 \mathrm{~L}$ iron tailings wastewater mentioned above at every turn to conduct oxidation-sedimentation experiment. When the wastewater was heated to the desired temperature, sodium hypochlorite (10\% of available chlorine) was added. After stirring the mixture for the desired time, $\mathrm{FeCl}_{2}$ were added to the mixture, and the KI-starch paper was used to detect the reaction progress until it did not change blue. Afterwards, the $\mathrm{pH}$ was adjusted to 9 10 with $\mathrm{NaOH}$ solution. After several hours of standing, the supernatant was separated, and then the PAM concentration, $\mathrm{COD}$ value, and $\mathrm{Ca}^{2+}$ content were measured.

2.4. Batch Flotation Tests. The bench-scale flotation tests were conducted in a XFD-63 flotation cell (self-aeration) whose volume for rougher flotation and cleaning flotation was $0.5 \mathrm{~L}$, using $200 \mathrm{~g}$ ore at every turn to obtain a Fe concentrate. Fatty acids (RA-715) were used as collector, 


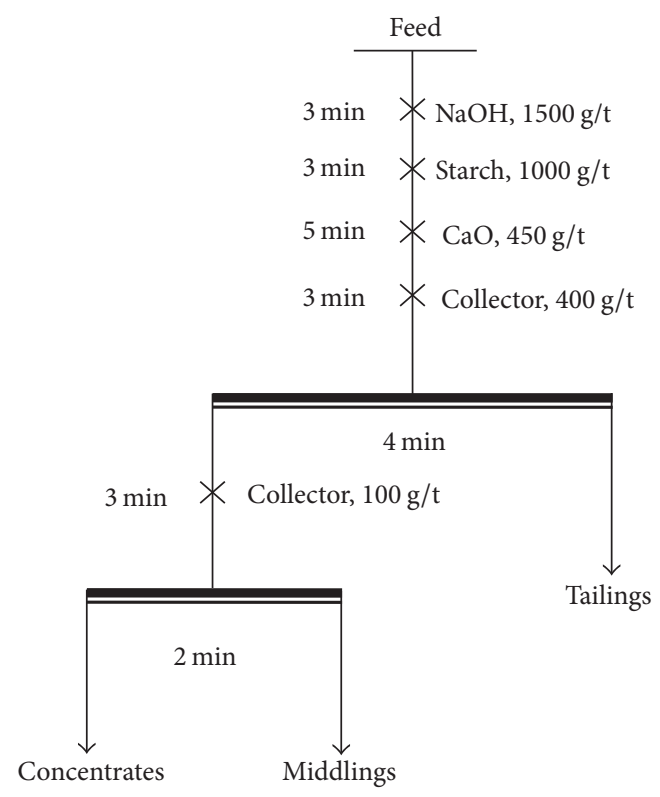

FIGURE 2: Flow sheet of flotation test.

$\mathrm{NaOH}$ was used as $\mathrm{pH}$ regulators, starch was used as depressant, and $\mathrm{CaO}$ was used as activator. The flotation flow sheet was illustrated in Figure 2.

2.5. FTIR Spectrum. The infrared spectra of samples were recorded by Nicolet AVATAR370 FTIR spectrometer (USA) using the $\mathrm{KBr}$ disk technique. The quartz samples used for this purpose were ground in an agate mortar and pestle to pass $5 \mu \mathrm{m} .50 \mathrm{mg}$ of samples was mixed with $30 \mathrm{~mL}$ distilled water in the absence or presence of $100 \mathrm{mg} / \mathrm{L}$ coagulant at $\mathrm{pH}$ 9 and $25^{\circ} \mathrm{C}$. After stirring for $3 \mathrm{~min}$, still standing for $4 \mathrm{~h}$, the solid product in the mixture was filtrated and rinsed three times and then dried in a vacuum oven and recorded infrared adsorption spectra from $400 \mathrm{~cm}^{-1}$ to $4000 \mathrm{~cm}^{-1}$.

2.6. Zeta Potential Measurements. Zeta potentials of HIMS tailings samples were measured by using a Brookhaven ZetaPlus zeta potential analyzer (USA). The samples used for this purpose were ground to less than $5 \mu \mathrm{m}$ in an agate mortar and pestle. $50 \mathrm{mg}$ of the samples was added to $30 \mathrm{~mL}$ aqueous solution with or without $100 \mathrm{mg} / \mathrm{L}$ coagulant. After stirring for $10 \mathrm{~min}$, then the $\mathrm{pH}$ values were adjusted with $\mathrm{HNO}_{3}$ or $\mathrm{NaOH}$ solutions and measured. All measurements were conducted in a $0.1 \mathrm{~mol} / \mathrm{L} \mathrm{KNO}_{3}$ background electrolyte solution. The agitated suspension was sampled to record the zeta potential. The results presented were the average of five independent measurements with a typical variation of $\pm 5 \mathrm{mV}$.

\section{Results and Discussion}

3.1. Effects of Components Contained in Tailings Wastewater on Flotation Process. Bench-scale flotation studies on the process water showed that tailings wastewater reduced the flotation iron concentrate grade and iron recovery [25]. Large doses of coagulants such as PAM and PDADMAC were used in wastewater treatment in Yuanjiacun concentrator previously. Only in the part of HIMS tailings concentration, doses of PAM and PDADMAC were several times of other similar mines [25]. In order to assess the practicability of recycling of process water in flotation practice, the influence of tailings wastewater components of PAM, PDADMAC, $\mathrm{Ca}^{2+}$, and $\mathrm{Cl}^{-}$ions was investigated independently. The results were shown in Figure 3.

Figures 3(a) and 3(b) showed that an increasing PAM or PDADMAC concentration reduced the iron flotation recovery. However there was very little reduction in iron grade. When the concentration increased from $0 \mathrm{mg} / \mathrm{L}$ to $3 \mathrm{mg} / \mathrm{L}$ for PAM and $0 \mathrm{mg} / \mathrm{L}$ to $30 \mathrm{mg} / \mathrm{L}$ for PDADMAC, the recoveries of iron decreased from $74.66 \%$ to $66.74 \%$ and $74.66 \%$ to $64.63 \%$, respectively. Figure 3(c) demonstrated that an increasing $\mathrm{Ca}^{2+}$ ions concentration reduced the iron grade and increased the iron flotation recovery obviously. When the concentration of $\mathrm{Ca}^{2+}$ ions increased from $0 \mathrm{mg} / \mathrm{L}$ to $180 \mathrm{mg} / \mathrm{L}$, the iron grade of concentration decreased from $66.27 \%$ to $64.42 \%$; the iron grade decreased sharply on addition of $360 \mathrm{mg} / \mathrm{L}$. However there was a slight increase in recovery in process water in presence of a number of $\mathrm{Ca}^{2+}$ ions. Figure 3(d) showed that, with increasing the dose of $\mathrm{Cl}^{-}$, there was no change in iron grade and recovery decreased only slightly.

3.2. Coagulating Sedimentation Experiments. Single factor tests of components contained in tailings wastewater showed that PAM, PDADMAC, and $\mathrm{Ca}^{2+}$ ions reduced the flotation iron recovery or grade of the concentrate. The origins of PAM, PDADMAC, and other organic species in tailings wastewater were the coagulants, flocculants, and flotation reagents such as PAM and PDADMAC for coagulating sedimentation of concentration and wastewater treatment, starch for depressing hematite flotation, and RA-715 for flotation of activated silicate minerals. The origin of calcium species in tailings wastewater was the ore and flotation reagents such as lime for activating $\mathrm{SiO}_{2}$ and silicate minerals. The method of coagulating sedimentation was used in the process of concentration of HIMS tailings, flotation concentrate and flotation tailings, and treatment of wastewater of tailings pond in Yuanjiacun concentrator. In order to lower the content of suspended solids, PAM, and PDADMAC, coagulating sedimentation experiments were conducted with a novel coagulant $\mathrm{CYH}$. Given the maximum amount of coagulants and flocculants used in HIMS tailings concentration in Yuanjiacun concentrator at present, we chose coagulating sedimentation testes of HIMS tailings concentration as a representative for detailed investigations to study the performance of $\mathrm{CHY}$.

Figure 4 exhibited the effect of PDADMAC or $\mathrm{CYH}$ dosage on coagulation efficiency by using PAM as a flocculant at $26.88 \mathrm{~g} /(\mathrm{t}$ undressed ore, the same below) initial concentration. The results in Figure 4 showed that, at the coagulant dosage of $8.96 \mathrm{~g} / \mathrm{t}$, the settle rate of $\mathrm{CYH}$ was faster than that of PDADMAC, even faster than that of PDADMAC at the dosage of $17.92 \mathrm{~g} / \mathrm{t}$. The turbidity of liquid supernatant by using $\mathrm{CYH}$ as a coagulant at $8.96 \mathrm{~g} / \mathrm{t}$ initial concentration was lower than that of PDADMAC same as that of initial concentration and was rough equal to that of PDADMAC as 


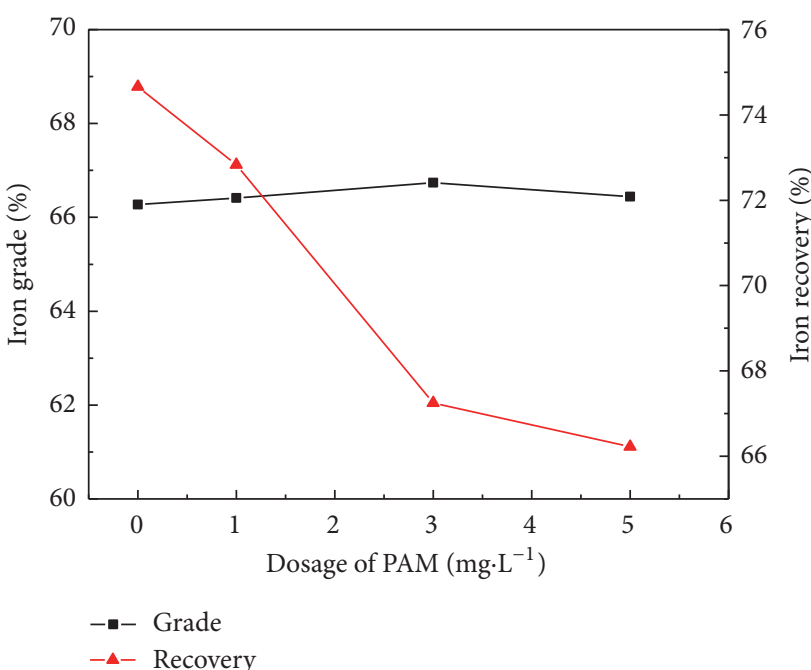

(a)

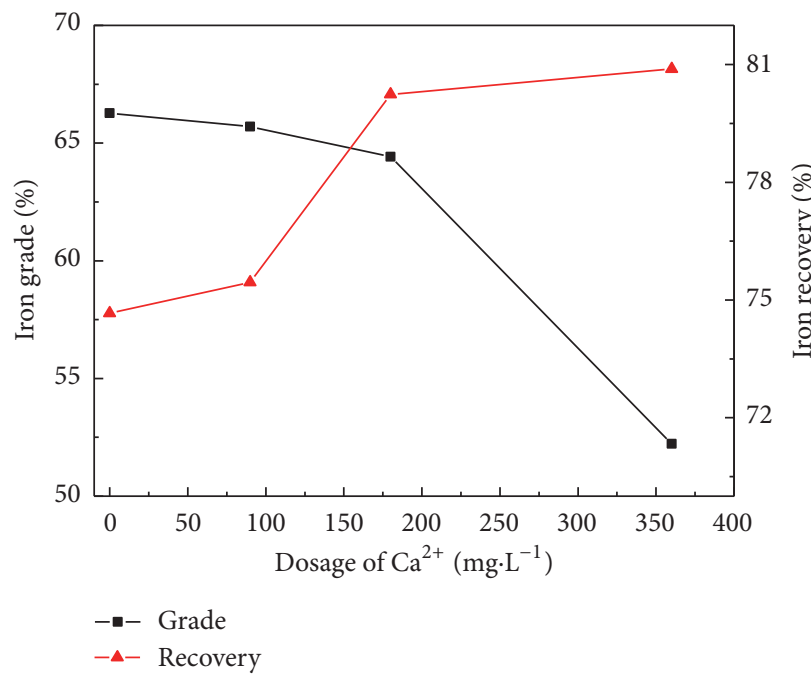

(c)

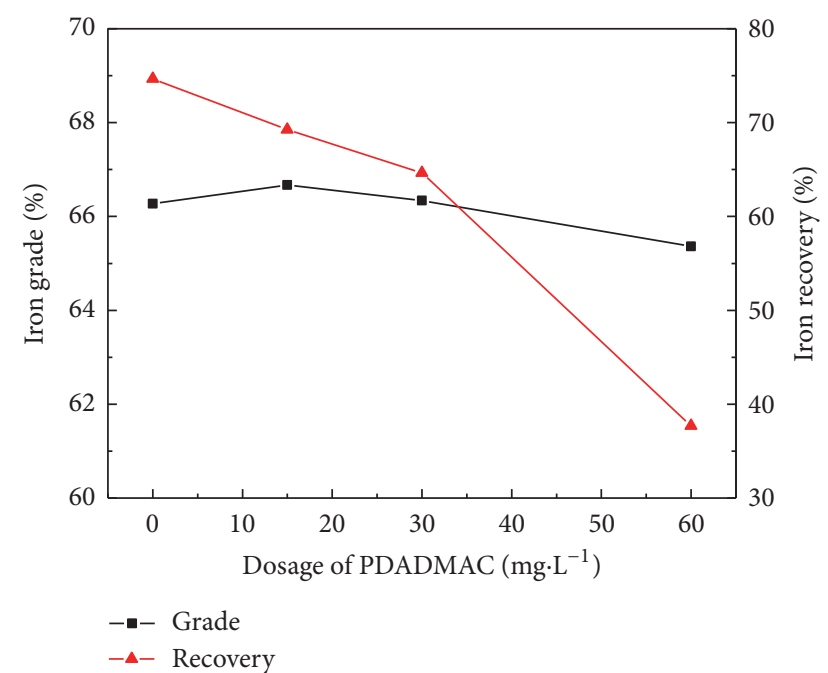

(b)

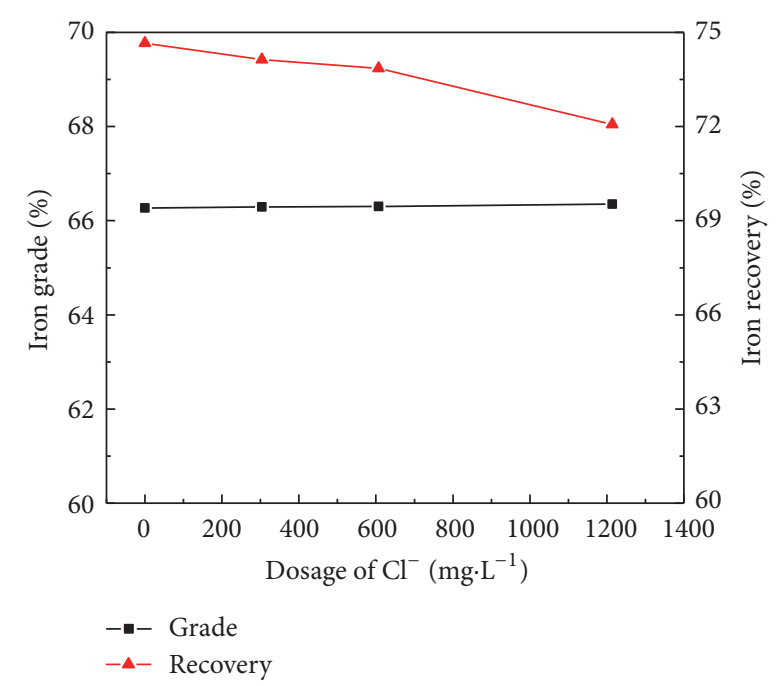

(d)

Figure 3: Effects of PAM (a), PDADMAC (b), $\mathrm{Ca}^{2+}(\mathrm{c})$, and $\mathrm{Cl}^{-}$(d) on flotation process.

a coagulant at $17.92 \mathrm{~g} / \mathrm{t}$ initial concentration. When the initial concentration of CYH increased from $8.96 \mathrm{~g} / \mathrm{t}$ to $17.92 \mathrm{~g} / \mathrm{t}$, the settle rate and turbidity changed little. Compared with PDADMAC, CYH exhibited superior coagulating ability.

The flocculation response of PAM as a function of initial concentration by using $\mathrm{CYH}$ as a coagulant at $8.96 \mathrm{~g} / \mathrm{t}$ initial concentration was presented in Figure 5. As it could be observed from Figure 5, the settle rate rapidly increased with increasing flocculant concentration. However, increasing PAM concentration had minor influence on turbidity of liquid supernatant.

3.3. FTIR Spectrum Analysis. As shown in Figure 1, quartz was the highest content of mineral in HIMS tailings. So, we chose quartz as a representative for FTIR spectrum investigation to study the adsorption mechanism of quartz before and after interaction with CYH. The FTIR spectra were presented in Figure 6.
Figure 6 showed that, after interaction with $\mathrm{CYH}$, the stretching and bending vibrations of saturated $\mathrm{C}-\mathrm{H}$ bonds in CYH molecules appeared at around 2962.17, 2933.24, 2871.53, and $1432.15 \mathrm{~cm}^{-1}$ on quartz surfaces, respectively. The results of FTIR spectra exhibited that, after CYH treatment, new adsorption peaks on quartz surfaces did not appear except for CYH's adsorption bands, which inferred that CYH might adsorb onto quartz surface without the formation of new complexes.

3.4. Zeta Potential Measurement. Zeta potentials of HIMS tailings particles as a function of $\mathrm{pH}$ values in the absence and presence of $\mathrm{CYH}$ were shown in Figure 7. It indicated that the potential of HIMS tailings was high. So coagulating sedimentation treatment of HIMS tailings was rather difficult from a certain degree because of the electrostatic repulse force among particles. As it could be observed from Figure 7, $\mathrm{CYH}$ could lower $\zeta$-potential values within the scope of $\mathrm{pH}$ 


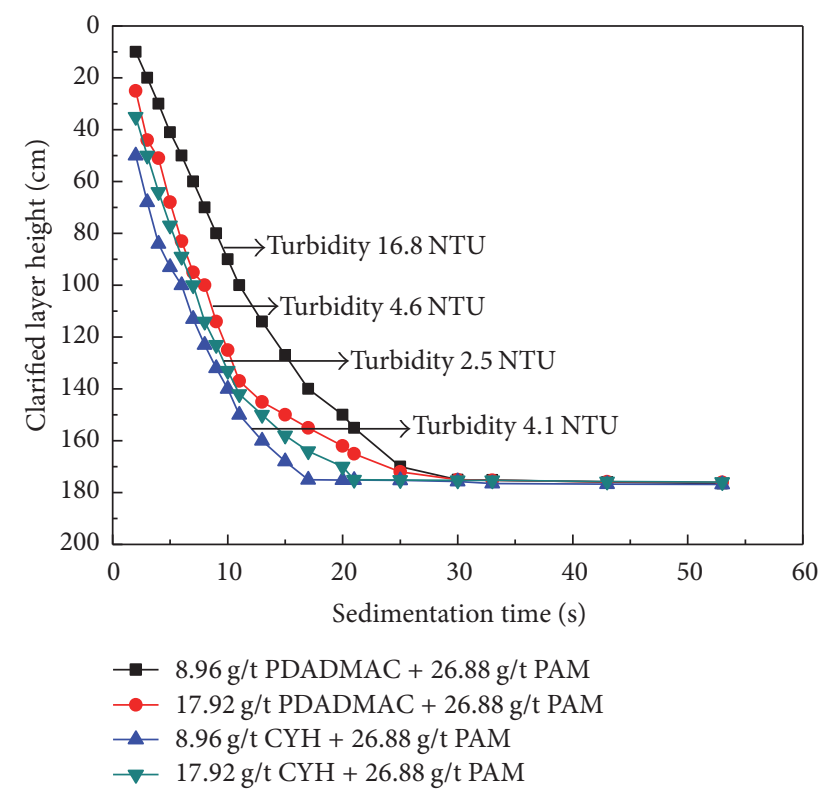

Figure 4: Effect of coagulation at different PDADMAC and CYH dosage.

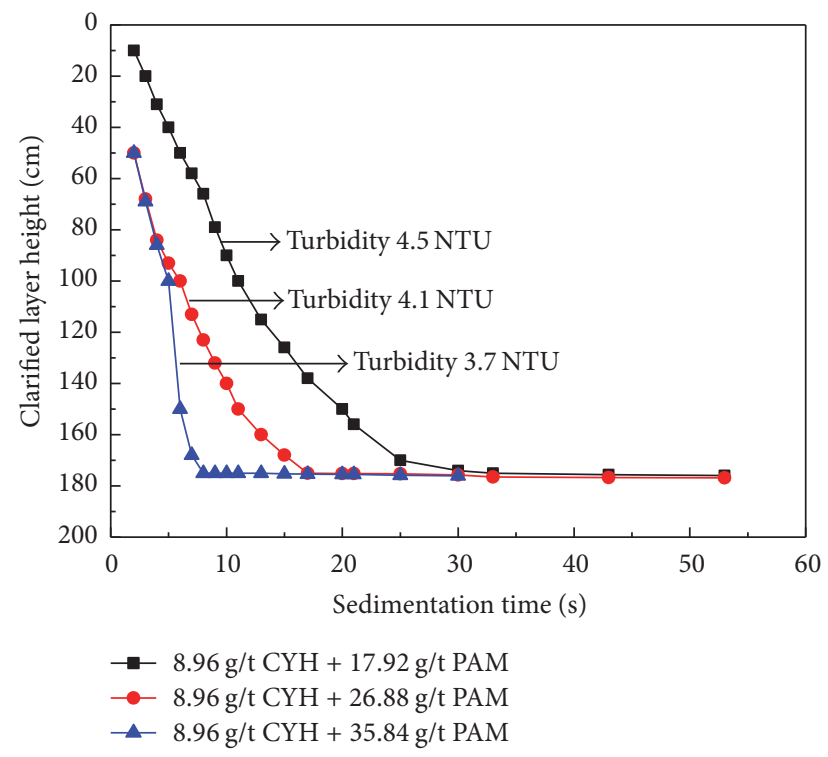

Figure 5: Effect of coagulation at different PAM dosage.

5 12, inferring that cationic CYH might adsorb onto particles surfaces. The results of zeta potential indicated that $\mathrm{CYH}$ adsorbed onto HIMS tailings mainly through electrostatic attraction, which agreed with the FTIR spectra results.

$\mathrm{CYH}$ that is a good coagulant has strong binding force by using hydroxy. After the mixture of HIMS tailings and $\mathrm{CYH}$, the stable silicate mineral groups in the wastewater were exposed; meanwhile, $\mathrm{CYH}$ entered into the wastewater and hydrolyzed strongly to be a polyhydroxy polymer compound. CYH adsorbed characteristically onto particles surfaces through electrostatic force, hydrogen bond, hydrophobic association, and van der Waals force, bridging the various

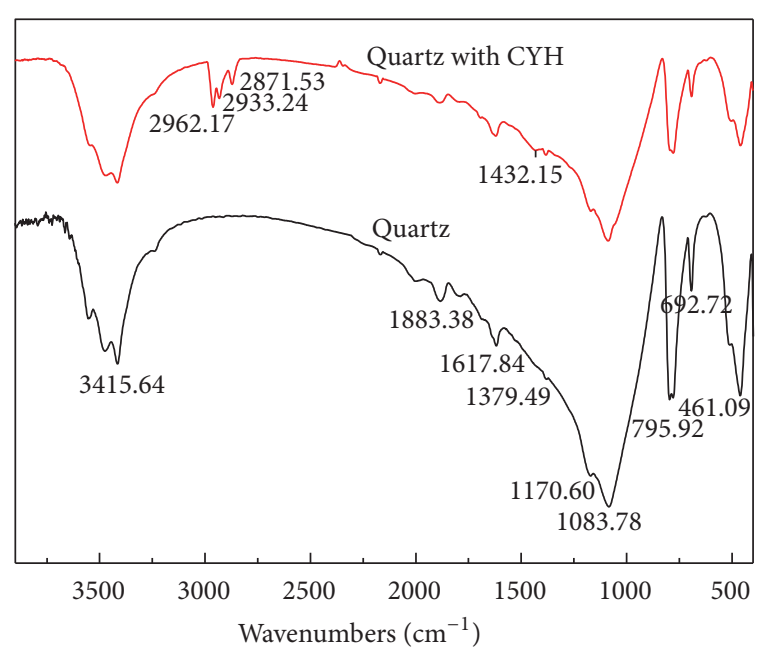

FIGURE 6: FTIR spectra of quartz before and after interaction with $\mathrm{CYH}$.

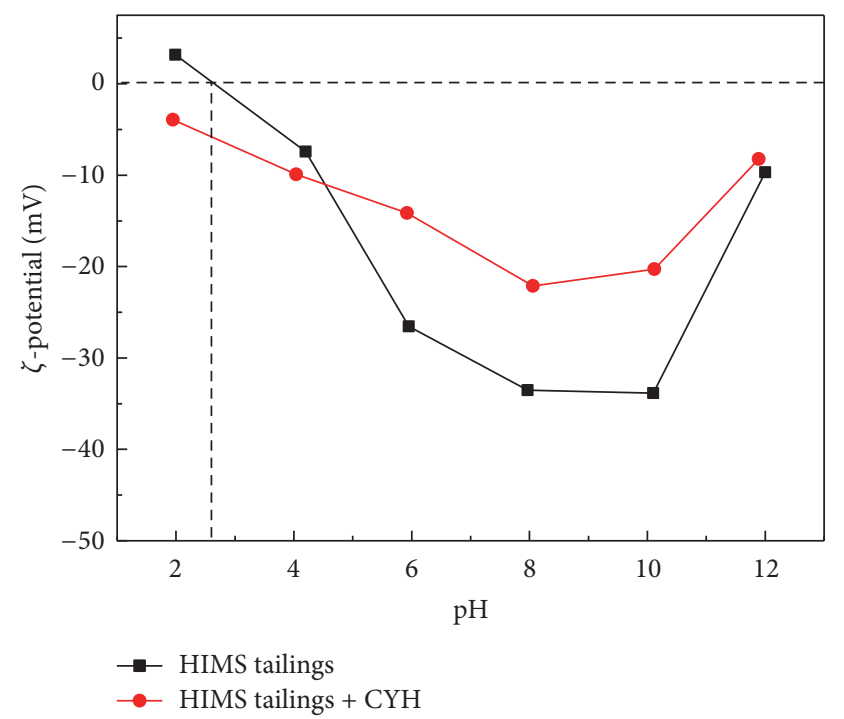

FIGURE 7: The zeta potential of HIMS tailings as a function of $\mathrm{pH}$ in the absence and presence of $\mathrm{CYH}$.

silicate minerals in the long $\mathrm{CYH}$ chain, forming large flocs to reach rapid subsidence through trapping and rolling.

\subsection{Oxidation-Sedimentation Treatment of Clarified Tailings} Wastewater. Table 3 showed that, by using $\mathrm{CYH}$ as a coagulant, the content of SS of tailings wastewater decreased obviously, and the wastewater became clear. However, the COD value and concentration of PAM in tailings water were still much higher than freshwater. The tailings water still could not meet the requirements of reuse for flotation. Thus, oxidation-sedimentation treatment was still needed in the process.

We chose removal rates of PAM and COD as representatives for detail investigations to study the effect of reaction parameters. Figure 8(a) showed the effect of dosage of sodium hypochlorite $(\mathrm{NaClO})$ on the removal rates of PAM and COD. 
TABLE 3: Rendering of CYH treating tailings wastewater.

\begin{tabular}{|c|c|c|c|c|c|c|}
\hline Water index & $\mathrm{pH}$ & $\mathrm{SS} /\left(\mathrm{mg} \cdot \mathrm{L}^{-1}\right)$ & $\mathrm{Ca}^{2+} /\left(\mathrm{mg} \cdot \mathrm{L}^{-1}\right)$ & $\mathrm{TFe} /\left(\mathrm{mg} \cdot \mathrm{L}^{-1}\right)$ & $\mathrm{PAM} /\left(\mathrm{mg} \cdot \mathrm{L}^{-1}\right)$ & $\mathrm{COD} /\left(\mathrm{mg} \cdot \mathrm{L}^{-1}\right)$ \\
\hline Tailings wastewater & 9.12 & 178 & 240 & 4.97 & 3.15 & 131 \\
\hline $\begin{array}{l}\text { Tailings wastewater after } \\
\text { coagulating sedimentation } \\
\text { treatment }\end{array}$ & 9.15 & 75 & 196 & 3.86 & 2.81 & 103 \\
\hline Freshwater & 7.94 & 45 & 142 & 0.19 & 0.26 & 4 \\
\hline
\end{tabular}

TABLE 4: Water quality monitoring data table.

\begin{tabular}{|c|c|c|c|c|c|c|}
\hline Water index & $\mathrm{pH}$ & $\mathrm{SS} /\left(\mathrm{mg} \cdot \mathrm{L}^{-1}\right)$ & $\mathrm{Ca}^{2+} /\left(\mathrm{mg} \cdot \mathrm{L}^{-1}\right)$ & $\mathrm{TFe} /\left(\mathrm{mg} \cdot \mathrm{L}^{-1}\right)$ & $\mathrm{PAM} /\left(\mathrm{mg} \cdot \mathrm{L}^{-1}\right)$ & $\mathrm{COD} /\left(\mathrm{mg} \cdot \mathrm{L}^{-1}\right)$ \\
\hline Tailings wastewater & 9.12 & 178 & 240 & 4.97 & 3.15 & 131 \\
\hline $\begin{array}{l}\text { Tailings wastewater } \\
\text { after treatment }\end{array}$ & 9.35 & 48 & 36 & 0.36 & 0.30 & 21 \\
\hline Freshwater & 7.94 & 45 & 142 & 0.19 & 0.26 & 4 \\
\hline
\end{tabular}

TABLE 5: The results of oxidation-sedimentation treatment on the reverse flotation of hematite.

\begin{tabular}{|c|c|c|c|c|}
\hline Flotation water & Product & Yield/\% & Grade/\% & Recovery/\% \\
\hline \multirow{3}{*}{ Freshwater } & Concentrate & 48.80 & 65.14 & 73.97 \\
\hline & Tailing & 49.10 & 20.91 & 23.89 \\
\hline & Feed & 100.00 & 42.97 & 100.00 \\
\hline \multirow{3}{*}{ Tailings wastewater } & Concentrate & 47.90 & 64.20 & 70.74 \\
\hline & Tailing & 49.45 & 23.46 & 26.69 \\
\hline & Feed & 100.00 & 43.47 & 100.00 \\
\hline \multirow{3}{*}{$\begin{array}{l}\text { Tailings wastewater } \\
\text { after treatment }\end{array}$} & Concentrate & 48.85 & 65.45 & 73.49 \\
\hline & Tailing & 49.80 & 21.89 & 25.06 \\
\hline & Feed & 100.00 & 43.51 & 100.00 \\
\hline
\end{tabular}

As shown in Figure 8(a), the removal rates of PAM and COD rapidly increased with increasing $\mathrm{NaClO}$ concentration when it was less than $1.0 \mathrm{~g} / \mathrm{L}$ and then slowly increased and reached $90.48 \%$ and $83.97 \%$ at $1.0 \mathrm{~g} / \mathrm{L}$ dosage, respectively. As it could be observed from Figure 8(b), the removal rates of PAM and COD increased with increasing reaction temperature. When the reaction temperature increased from $15^{\circ} \mathrm{C}$ to $30^{\circ} \mathrm{C}$, the removal rates increased from $87.62 \%$ to $94.61 \%$ and $77.86 \%$ to $87.64 \%$ for $\mathrm{PAM}$ and $\mathrm{COD}$, respectively. The reaction temperature is higher, the reaction rate is faster, but the decomposition of $\mathrm{NaClO}$ is faster. The choice of $20^{\circ} \mathrm{C}$ as the reaction temperature can ensure $\mathrm{NaClO}$ has good oxidation ability, but also conform to the most of natural temperature of tailings wastewater in Yuanjiacun concentrator. Figure 8(c) demonstrated that the removal rates of PAM and COD rapidly increased with prolonging reaction time when it was less than $30 \mathrm{~min}$ and then maintained roughly constant.

3.6. Recycling of Treated Tailings Wastewater. The quality of tailings wastewater which had been gone through oxidationsedimentation treatment was shown in Table 4.

As shown in Table 4, after treatment by using oxidationsedimentation method, $\mathrm{pH}$ of tailings wastewater increased from 9.12 to 9.35 , suspended solids content decreased from $178 \mathrm{mg} / \mathrm{L}$ to $48 \mathrm{mg} / \mathrm{L}$, and concentration of $\mathrm{Ca}^{2+}$ ions, $\mathrm{TFe}$, PAM, and COD decreased from $240 \mathrm{mg} / \mathrm{L}$ to $36 \mathrm{mg} / \mathrm{L}$,
$4.97 \mathrm{mg} / \mathrm{L}$ to $0.36 \mathrm{mg} / \mathrm{L}, 3.15 \mathrm{mg} / \mathrm{L}$ to $0.30 \mathrm{mg} / \mathrm{L}$, and $131 \mathrm{mg} / \mathrm{L}$ to $21 \mathrm{mg} / \mathrm{L}$, respectively. And the removal rates of PAM, COD, and $\mathrm{Ca}^{2+}$ was $90.48 \%, 83.97 \%$, and $85.00 \%$, respectively. The water quality of treated tailings wastewater was close to the quality of freshwater.

Bench-scale flotation studies were conducted according to the procedure as shown in Figure 2. These studies would show whether oxidation-sedimentation treatment of the tailings wastewater occurring in the pilot plant had any effect on selectivity and/or recovery of minerals during flotation. Results were given in Table 5. The results showed that the concentrate yield, grade, and recovery increased by $0.95 \%, 1.25 \%$, and $2.75 \%$, respectively, by using treated tailings wastewater as flotation water compared to that of tailings wastewater without treatment. Compared to freshwater, in the case of the equivalent yield, treated tailings wastewater achieved an excellent concentration containing $65.45 \% \mathrm{Fe}$ with $73.49 \%$ Fe recovery, and the Fe grade increased by $0.31 \%$.

\section{Conclusions}

(1) Single factor tests of components contained in tailings wastewater in Yuanjiacun concentrator showed that PAM, PDADMAC, and $\mathrm{Ca}^{2+}$ ions reduced the flotation iron recovery or grade of the concentrate. 


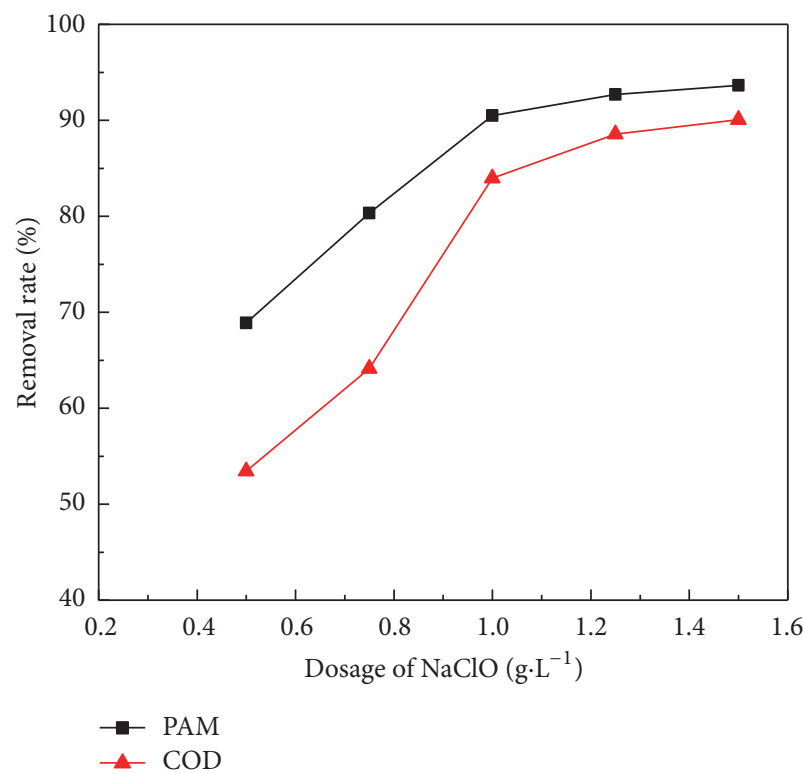

(a)

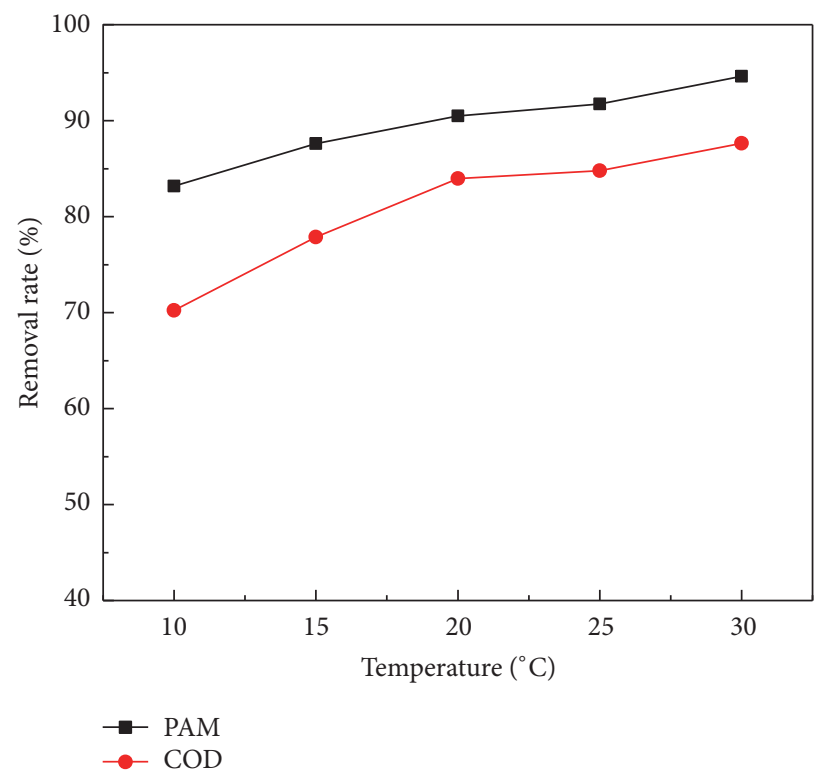

(b)

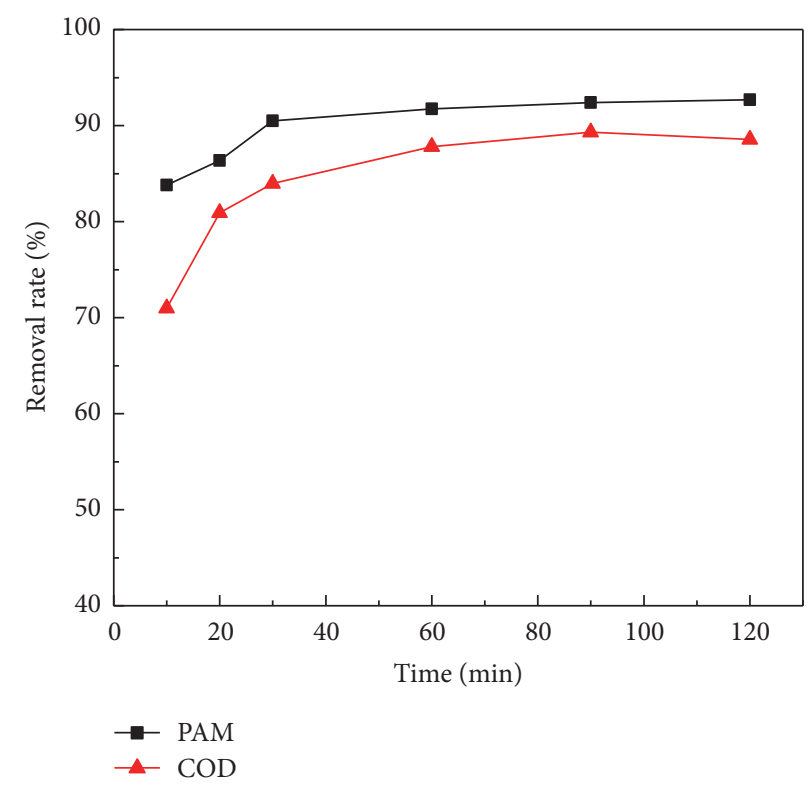

(c)

Figure 8: Effects of dosage of $\mathrm{NaClO}$ (a), reaction temperature (b), and reaction time (c) on the oxidation of tailings wastewater by using $\mathrm{NaClO}$ as oxidizing agent. Oximation conditions: (a) natural $\mathrm{pH}$; temperature, $20^{\circ} \mathrm{C}$; time, $30 \mathrm{~min}$; (b) natural $\mathrm{pH}$; dosage of $\mathrm{NaClO}, 1.0 \mathrm{~g} / \mathrm{L}$; time, $30 \mathrm{~min}$; (C) natural $\mathrm{pH}$; dosage of $\mathrm{NaClO}, 1.0 \mathrm{~g} / \mathrm{L}$; temperature, $20^{\circ} \mathrm{C}$.

(2) When CYH was used to coagulate HIMS tailings, $\zeta$ potential decreased, and silicate minerals formed flocculent mass by bridging; thus suspended matters decreased effectively. This was subsequently confirmed by FTIR spectrum and zeta potential analysis. But the tailings wastewater could not reach recycling standards.

(3) Oxidation experiment showed that a $90.48 \%$ reduction in PAM, $83.97 \%$ reduction in COD, and $85.00 \%$ reduction in $\mathrm{Ca}^{2+}$ were achieved at the sodium hypochlorite dosage of $1.0 \mathrm{~g} / \mathrm{L}$, reaction temperature of $20^{\circ} \mathrm{C}$, and reaction time of 30 minutes. Bench-scale flotation tests on the treated tailings wastewater indicated that the Fe recovery and grade of concentrate were close to those of freshwater.

\section{Conflicts of Interest}

The authors declare that they have no conflicts of interest.

\section{Acknowledgments}

The authors gratefully acknowledge the financial supports of the National Natural Science Foundation of China (no. 
5160041305) and the China Postdoctoral Science Foundation (no. 2016M591382). This project is also supported by Lanxian County Mine Co., Ltd., TISCO, China.

\section{References}

[1] Y. X. Han, Y. S. Sun, Y. J. Li, and P. Gao, "New development on mineral processing technology of iron ore resources in China," Metal Mine, vol. 143, pp. 87-97, 2015.

[2] X. Ma, M. Marques, and C. Gontijo, "Comparative studies of reverse cationic/anionic flotation of Vale iron ore," International Journal of Mineral Processing, vol. 100, no. 3-4, pp. 179-183, 2011.

[3] L. O. Filippov, I. V. Filippova, and V. V. Severov, "The use of collectors mixture in the reverse cationic flotation of magnetite ore: The role of Fe-bearing silicates," Minerals Engineering, vol. 23, no. 2, pp. 91-98, 2010.

[4] A. C. Araujo, P. R. M. Viana, and A. E. C. Peres, "Reagents in iron ores flotation," Minerals Engineering, vol. 18, no. 2, pp. 219224, 2005.

[5] A. M. Vieira and A. E. C. Peres, "The effect of amine type, $\mathrm{pH}$, and size range in the flotation of quartz," Minerals Engineering, vol. 20, no. 10, pp. 1008-1013, 2007.

[6] Z. Huang, H. Zhong, S. Wang, L. Xia, W. Zou, and G. Liu, "Investigations on reverse cationic flotation of iron ore by using a Gemini surfactant: Ethane-1,2-bis(dimethyl-dodecylammonium bromide)," Chemical Engineering Journal, vol. 257, pp. 218-228, 2014.

[7] F. Ikumapayi, M. Makitalo, B. Johansson, and K. H. Rao, "Recycling of process water in sulphide flotation: effect of calcium and sulphate ions on flotation of galena," Minerals Engineering, vol. 39, pp. 77-88, 2012.

[8] S. R. Rao and J. A. Finch, "A review of water re-use in flotation," Minerals Engineering, vol. 2, no. 1, pp. 65-85, 1989.

[9] J. Wang, G. He, B. Fan, and J. Xiao, "Research on technology of wastewater treatment from scheelite flotation," Advanced Materials Research, vol. 645, pp. 121-124, 2013.

[10] Y. Ma, B. Q. Hu, and Z. X. Sun, "The summary of studies on the acid mine drainage treatment," Minerals Engineering, vol. 4, no. 3, 55 pages, 2006.

[11] D. Feng, J. S. J. Van Deventer, and C. Aldrich, "Removal of pollutants from acid mine wastewater using metallurgical byproduct slags," Separation and Purification Technology, vol. 40, no. 1, pp. 61-67, 2004.

[12] A. Blanco, E. Fuente, M. C. Monte, N. Cortés, and C. Negro, "Polymeric branched floeeulant effeet on the floeculation proeess of pulp suspensions in the papermaking industry," Industrial \& Engineering Chemistry Research, vol. 48, no. 10, pp. 4826-4836, 2009.

[13] R. Mitra and L. Tauxe, "Full vector model for magnetization in sediments," Earth and Planetary Science Letters, vol. 286, no. 34, pp. 535-545, 2009.

[14] H. Zhang, Z. Zhao, X. Xu, and L. Li, "Study on industrial wastewater treatment using superconducting magnetic separation," Cryogenics, vol. 51, no. 6, pp. 225-228, 2011.

[15] T. J. Wan, S. M. Shen, S. H. Siao, C. F. Huang, and C. Y. Cheng, "Using magnetic seeds to improve the aggregation and precipitation of nanoparticles from backside grinding wastewater," Water Research, vol. 45, no. 19, pp. 6301-6307, 2011.

[16] J. R. Parga, S. S. Shukla, and F. R. Carrillo-Pedroza, "Destruction of cyanide waste solutions using chlorine dioxide, ozone and titania sol," Waste Management, vol. 23, no. 2, pp. 183-191, 2003.
[17] H. Brix, "Treament of wastewater in the rhizosphere of wetland plants the root-zone method," Water Science and Technology, vol. 19, 107 pages, 1987.

[18] J. Vymazal, "Constructed wetlands for wastewater treatment in the Czech Republic the first 5 years experience," Water Science and Technology, vol. 34, no. 11, pp. 159-164, 1996.

[19] S. Khan, I. Ahmad, M. T. Shah, S. Rehman, and A. Khaliq, "Use of constructed wetland for the removal of heavy metals from industrial wastewater," Journal of Environmental Management, vol. 90, no. 11, pp. 3451-3457, 2009.

[20] H. Y. Zhao and S. L. Zhu, "Removal of chromium ions in an expand ion-exchange bed," Journal of Tsinghua University (Science and Technology), vol. 43, 1309 pages, 2003.

[21] E. I. El-Shafey, M. Cox, A. A. Pichugin, and Q. Appleton, "Application of a carbon sorbent for the removal of cadmium and other heavy metal ions from aqueous solution," Journal of Chemical Technology and Biotechnology, vol. 77, no. 4, pp. 429436, 2002.

[22] C. A. Eligwe and N. B. Okolue, "Adsorption of iron(II) by a Nigerian brown coal," Fuel, vol. 73, no. 4, pp. 569-572, 1994.

[23] C. M. Neculita and G. J. Zagury, "Biological treatment of highly contaminated acid mine drainage in batch reactors: Long-term treatment and reactive mixture characterization," Journal of Hazardous Materials, vol. 157, no. 2-3, pp. 358-366, 2008.

[24] T. Jong and D. L. Parry, "Removal of sulfate and heavy metals by sulfate reducing bacteria in short-term bench scale upflow anaerobic packed bed reactor runs," Water Research, vol. 37, no. 14, pp. 3379-3389, 2003.

[25] H. F. Xu, W. Chen, W. F. Li, and B. Yang, "Experimental study on beneficiation wastewater treatment and reuse of Yuan-jiacun iron ore in Shanxi," Mining and Metallurgical Engineering, vol. 36, pp. 270-274, 2016. 

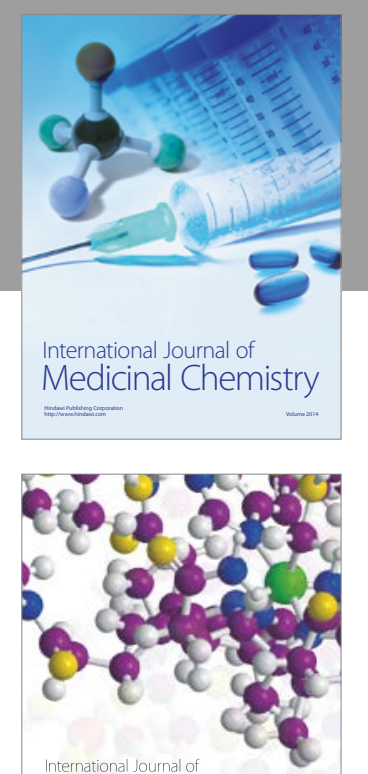

Carbohydrate Chemistry

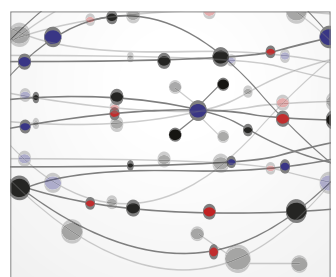

The Scientific World Journal
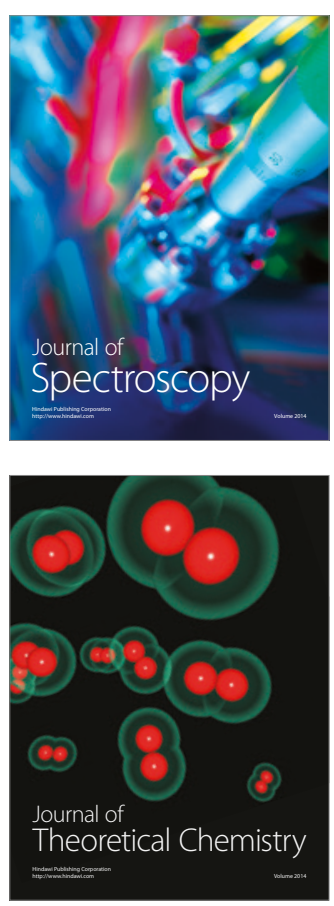
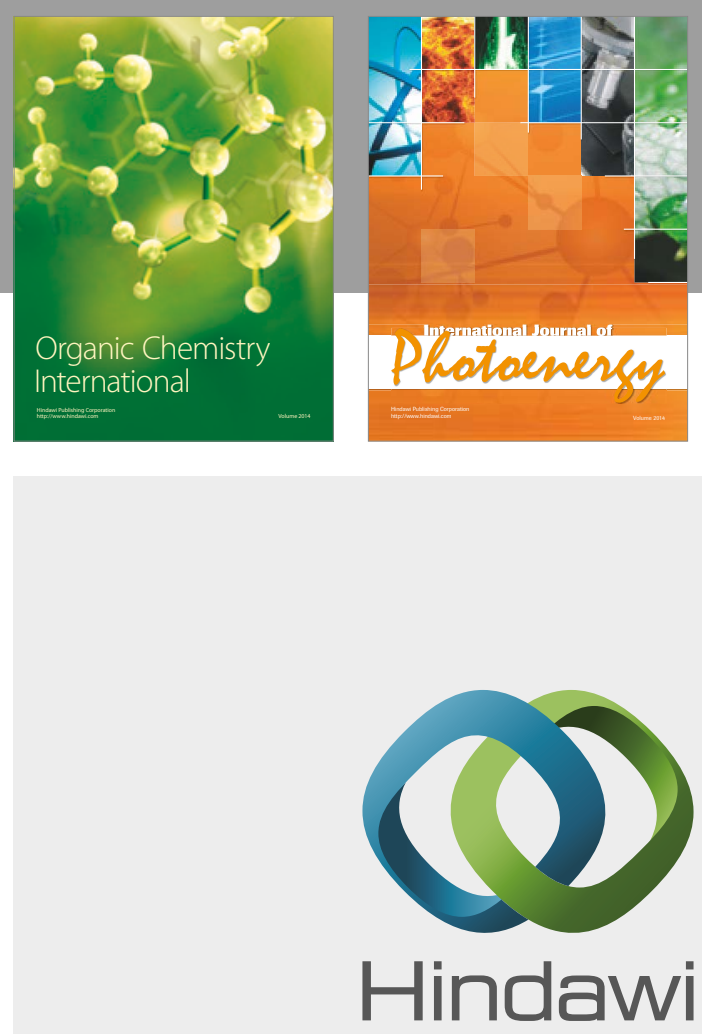

Submit your manuscripts at

https://www.hindawi.com

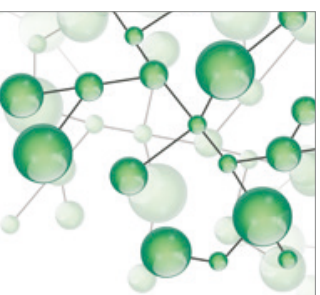

International Journal of

Inorganic Chemistry

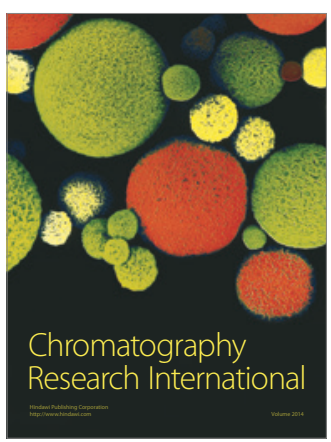

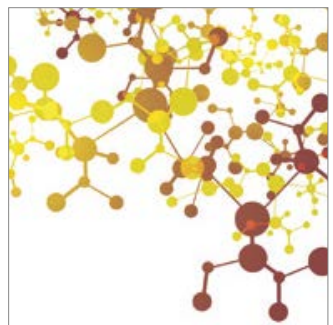

Applied Chemistry
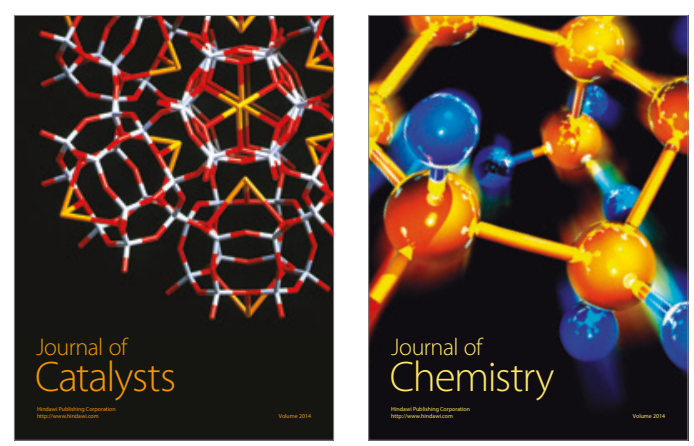
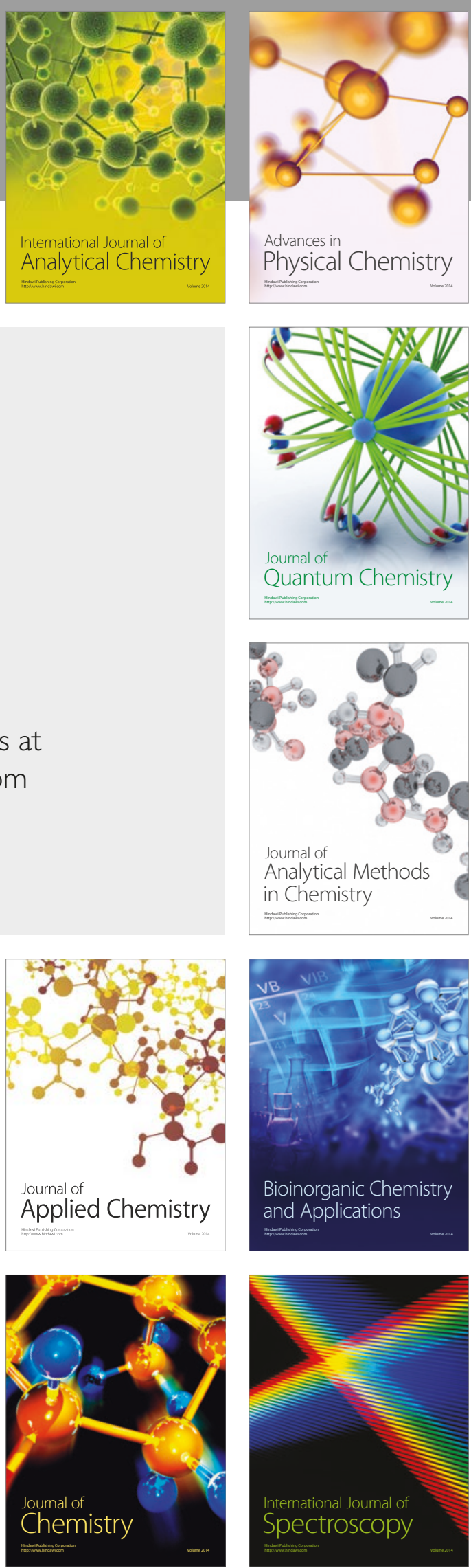